\title{
Caring values in undergraduate nurse students: a qualitative longtitudinal study
}

Rosser, E., Scammell, J., Heaslip, V., White, S., Phillips, J., Cooper, K., Donaldson, I., Hemingway, A.,

\section{$\underline{\text { ABSTRACT }}$}

Introduction: Given the emerging evidence internationally of poor care within the healthcare sector, a recent report in the United Kingdom recommended the need for education to produce nurses who are prepared both intellectually and with compassion.

Aim: This paper aims to understand the beliefs and values of caring, held by student nurses from entry to completion of their education programme.

Methods: Using a prospective qualitative longtitudinal approach, two cohorts of nursing students (February 2013 and 2014) each following a different undergraduate curriculum (the February 2013, based on a philosophy of person-centred care and the February 2014, based on the philosophy of humanisation) were followed throughout their programme leading to Registration. Data were collected from February 2013 to February 2017 using individual interviews at commencement and completion of their programme with focus groups after their first placement and at the end of years one and two. Using purposive sampling, from February 2013, 12 commenced the study and five finished. From February 2014, 24 started, with nine completing.

Findings: Data were analysed using thematic analysis with four themes emerging: i) Articulating the terms caring and dignity ii) Recognising the need for individualisation iii) Learning nursing and iv) Personal journey.

Conclusion: Reporting on the final phase of this 5-phase study and on the brink of qualifying, both cohorts of students recognised the impact of their different curriculum and their exposure to the same educators who had embraced the humanisation philosophy. They each acknowledged just how they had changed as individuals and how determined they were to influence the quality of care.

\section{INTRODUCTION}

A number of high profile reports (Francis 2013, Berwick 2013, Keogh 2013) sparked a fury within the United Kingdom (UK) National Health Service (NHS) about the emerging evidence 
of poor care within the healthcare sector in England. This resulted in a proliferation of reviews, professional frameworks and discussion papers (Health Education England [HEE] 2015, Department of Health [DH] 2012, HEE 2016) emphasising the need for care to be person-centred, compassionate and well informed. However, evidence of poor care is not limited to the UK. There has been an explosion of papers published globally on the need to return to first principles of a values-based profession, balanced against a focus on a target driven service based on measureable outcomes and efficiencies (eg. Salehian, et al. 2017, Aupia et al. 2017). Following recommendations from the initial reports, the Chief Nurse of England published her vision and strategy for nursing to reform the direction of care, build on the already founding values as stated in the NHS Constitution (DH 2015) and deliver high quality, compassionate care (DH 2012). At the same time, critical scrutiny was given to nurse education, with Lord Willis concluding that 'Our education system must produce nurses who have both intellect and compassion, not one or the other' (RCN 2012:p4), with the professional regulators promoting the benefits of overt 'values-based' curricula as well as recruitment processes (Nursing and Midwifery Council [NMC] 2010, HEE 2016).

In response, one faculty of health in the south of England chose to base their nurse curriculum on a philosophy of humanisation (Todres et al., 2009) and to evaluate the impact of this on students' perceptions of their values of caring throughout their undergraduate nursing programme. We reported on the early phase of the evaluation (Phillips et al., 2015); the purpose of this paper is to report on the final phase of a five-phase case study which uses a prospective qualitative longitudinal approach (Neal 2013) to understand the beliefs and values of caring, held by student nurses from the day of entry through their education programme to completion.

\section{BACKGROUND}

The theoretical model of the humanising values framework (HVF) devised by Todres et al., (2009) presents a framework of eight interrelated dimensions of what it means to be human (see Table 1). Each dimension is located on a continuum with humanised care at one end and dehumanised care at the other. In designing a new curriculum it is important to make its underpinning philosophy overt for all stakeholders and to ensure that this is embedded 
throughout the design and delivery processes. The HVF was selected because it embodies an approach to practice that enables students to understand potentially humanising and dehumanising aspects of caring systems and interactions and to self-appraise and amend their practice accordingly (Scammell and Tait 2014).

Table 1 Humanising Values Framework. Dimensions of humanisation (Todres et al 2009)

\begin{tabular}{|l|l|}
\hline Forms of humanisation & Forms of dehumanisation \\
\hline Insiderness & Objectification \\
\hline Agency & Passivity \\
\hline Uniqueness & Homogenisation \\
\hline Togetherness & Isolation \\
\hline Sense making & Loss of meaning \\
\hline Personal journey & Loss of personal journey \\
\hline Sense of place & Dislocation \\
\hline Embodiment & Reductionism \\
\hline
\end{tabular}

As a theme throughout the programme, we were keen to understand in what way the philosophy of humanisation would actually impact on the students' values. Previous research investigating caring values and student nurses has highlighted strong caring values at programme commencement (Day et al. 2005), which became increasingly undermined as the course progressed (Mackintosh 2006; Murphy et al. 2009). However, specific links to the curriculum were not investigated.

Warne et al. (2011) reflected on the pedagogical challenges of preparing student nurses for contemporary practice, to develop, not just their technical knowledge and skills but also the need to nurture attitude and values required of professionals in practice. This reinforced our commitment to using a humanising values framework based on qualitative research to support our new curriculum but ensuring that we had a methodological approach which could 'measure' the difference between the new and outgoing curricula by involving the 
outgoing cohort of students who were following a curriculum based on a philosophy of person-centred care.

\section{METHODS}

\section{Research Design}

This paper reports on findings from the final phase of a Five Phase case study (see Table 2) which uses a prospective qualitative longitudinal approach (Neale 2013) to understand the beliefs and values of caring, held by student nurses from the day of entry through their education programme to completion. The researchers were particularly interested in the impact of the humanising curriculum on any change in the students' developing values as they progressed over time.

Two cohorts of students were recruited; the first (February 2013), from an outgoing Advanced Diploma programme based on a philosophy of person-centred care, and the second (February 2014), the new Bachelor of Science curriculum based on a humanisation philosophy (Todres et al. 2009). The two groups were carefully chosen as it was anticipated that a difference would be observed between the two cohorts given the two different underpinning curriculum philosophies. However, no such difference was found between the two student groups and it was recognised that both cohorts were taught by the same group of educators, who had embraced the new humanisation terminology and would likely be using this freely across the two groups The whole study explores the two cohorts at specific phases (see Table 2), seeking to identify any change in perceptions around caring and their values in relation to nursing.

Table 2 Data Collection

\begin{tabular}{l|l}
\hline February 2013 cohort & February 2014 cohort \\
\hline $\begin{array}{l}\text { Phase One } \\
\text { Individual interviews on day one of }\end{array}$ & $\begin{array}{c}\text { Phase One } \\
\text { the programme }\end{array}$ \\
Phase Two & Phase Two programme \\
\hline
\end{tabular}




\begin{tabular}{l|l}
\hline $\begin{array}{l}\text { Focus groups after first practice } \\
\text { placement }\end{array}$ & $\begin{array}{l}\text { Focus groups after first practice } \\
\text { placement } \\
\text { Phase Three }\end{array}$ \\
$\begin{array}{l}\text { - Focus groups at the end of year } 1 \\
\text { Phase Four }\end{array}$ & $\begin{array}{c}\text { Phase Four } \\
\text { - Focus groups at the end of year } 2\end{array}$ \\
Phase Five & $\begin{array}{c}\text { Phase Five } \\
\text { - Individual interviews at the end of }\end{array}$ \\
the programme & Individual interviews at the end of \\
\end{tabular}

\section{Research Ethics}

Ethical approval for the whole study was sought and granted from the university's research ethics committee. However, specifically related to the qualitative longitudinal approach, Neale (2013) discusses in some detail, the special ethical considerations that need to be given to research undertaken over time and particularly refers to the need for all researchers to adhere to well established ethical principles related to consent (requested at every data collection point) and maintaining confidentiality (all documents referred to participants using an allocated numerical code that was independent of the central records holding personal details and all data was kept on password protected computers). A verbal briefing outlining the project was given to students during an introductory session on day one of their programme and at each subsequent meeting, along with a written participant information sheet. Reassurance was given that participation in the study was completely voluntary and that they could withdraw from the project at any stage without penalty or have any negative impact upon their future studies.

\section{Sampling}

Targeting the Spring 2013 cohort of students (total $n=21$ ) a purposive sampling was used. Of these, 12 decided to participate, of which five remained with the study until the end of three years. Similarly 24 participants were recruited from the 2014 cohort, a Bachelor of Science Degree with a slightly larger intake $(n=27)$, with nine completing the study. 


\section{Data Collection}

Data collection took place by individual interview at commencement of their programme prior to any formal educational input (Phase 1) and again, during the final days of the programme (phase 5); and by focus groups after their first placement (phase 2) and at the end of their first (phase 3) and second years (phase 4). Overall, data were collected from February 2013 to February 2017. This paper reports the final stage from both cohorts (Table 2) during February 2016 and February 2017, at the end of their programme.

As a number of data collectors were involved, all followed the previously agreed data collection interview guide (Table 3) which was used for all data collection throughout the study. A predetermined set of questions ensured that all data collection focussed on the same topic areas (Holloway and Wheeler, 2010) with sufficient scope to enable a conversational flow as the study progressed (Cohen at al., 2007). This approach ensured consistency of interviews which was important for validity of the research process. The interviews and focus groups were undertaken at the university campus during a timetabled break attached to lunchtime to ensure ease for participants.

\section{Table 3 Phase One interview guide}

\section{Questions}

1. Why do you wish to become a registered nurse?

2. What do you think are the essential/ important qualities for a nurse to have?

3. Do you think you bring these qualities with you or, do you think you are here to learn these?

4. What do you understand the term 'caring' to mean?

5. What makes an ideal nurse from your perspective?

6. What are your ambitions to achieve on this programme?

7. How do you think the education programme will help you?

8. What activities do you think represents the maintenance of a patient's dignity? 


\section{Data Analysis}

Following each interview and focus group, the digital recordings were transcribed verbatim and analysed using a thematic analysis adapted from Braun and Clarke (2006). The 2014 cohort was then compared with the 2013 cohort once they reached the same phase in the study. Identification and review of themes occurred in a group setting with all researchers to ensure the integrity of the themes identified. In addition, all researchers were provided with a copy of the transcripts that had been analysed by each researcher to enable cross checking of codes. Once the overarching themes had been identified the data were then revisited to ensure consistency and to get a sense of the whole.

\section{FINDINGS}

As previously acknowledged, this paper presents the findings from the individual interviews at the end of their programme for each cohort (February 2013 or February 2014) and each participant will be referred to as either F13 or F14 alongside the number allocated as participant (eg F13:2) at the outset of the study. In comparison to the findings of phase 1 of the study (Phillips et al. 2015), at the end of their programme both cohorts were very similar in their articulation of their approach to both individualised care and the maintenance of dignity. Although each cohort followed a different curriculum, both were taught by the same academic staff who used the principles and language of humanisation theory (Todres et al.2009). Over the progress of the study, four overarching themes emerged:

1. Articulating the meaning of the terms caring and dignity.

2. Recognising the need for individualisation

3. Learning nursing.

4. Personal journey

\section{Articulating the meaning of the terms 'caring' and 'dignity'}

The meaning of the term 'caring'

At the early stages of the study, students found it difficult to articulate the meaning of caring and rather expressed themselves in negative terms as to what it is not. However, as their journey progressed, they were able to express themselves more confidently and comprehensibly. In particular, the F14 cohort offered numerous suggestions as to the 
meaning of caring and the qualities of a good nurse: "Empathising, being there for the patients, supporting them, advocating their wishes ...letting them know the risks." (F14:3), whilst the F13 students knew exactly what caring meant but were less fluent in their expression e.g. "Caring is about trying to do your best for [someone], putting them first... just basically doing the best thing for them.." (F13:2).

In Phase 1, both cohorts of students focused on the technical skills of nursing but by Phase 5 they were more understanding of more subtle ways of making a difference. Indeed, a wide range of qualities were articulated confidently about the qualities of a caring nurse from both groups: "I think compassion is... a big one.... to be able to challenge something if they think it's not right, and ...listening...to the patients.. to what they have to say. (F14:16); and: "To be patient...not to rush because some patients they need that bit of encouragement..to open up to (F14:16)".

Although many students at the outset of the study believed that caring and values could $\underline{\text { not }}$ be taught, that nurses either possessed a sound values base or not, now, at the end of the programme, their views had changed: "It (caring) has made more sense through the programme. I think um ..the concept of not doing to but being with was highlighted fairly early on and yeah I think I've kind of taken it with me through the training" (F13:3). "... it's not just the task that you are doing, it's...everything that surrounds" (F13:2).

The meaning of the term 'dignity'

Articulating the meaning of dignity was equally challenging to the students at the outset but now, at the end of their programme, they were less inclined to simply refer to the practice of privacy (closing curtains during intimate care) but were able to show insights into the complexity of the concept in terms of nurse-patient relationships: "I used to say that curtains,.. you know making sure that they are covered but I think it probably is making sure that they are heard and their needs are listened to and acted upon" (F13:4). 
Whilst some students acknowledged the different interpretations of dignity, many students from both groups recognised it was closely related to the notion of delivering personcentred care: "I think dignity can mean different things to different people .. Seeing the person as a whole and respecting .. the way in which they live; the way in which they wish to receive treatment; I think it's really all about patient centred care and that ultimately you respect dignity because you are respecting patient wishes and how they want to be treated (F14:16).

\section{Recognising the need for individualisation}

Whilst students in the F13 cohort referred to the individualisation of care, they also referred occasionally to humanised care, with almost all of the F14 cohort (humanisation curriculum) presenting a greater insight into the importance of humanisation and its relationship to each individual patient. One particular student acknowledged the difficulty she had in making sense of this as a theory, yet its application became real when exposed to the real world of practice: "... it made more sense [in practice] because you were able to see how you don't objectify people, you treat them as a person, to be respectful (F14:4).

Students in the F14 cohort (humanised curriculum) talked about needing to be adaptable to meet individual patient need, recognising the considerable responsibility expected of them. They acknowledged the need to act as patient advocate, the need for honesty and the importance of daily reflection.

By the end of the programme, almost all participants articulated their recognition of the need for individualised or humanised care. An example from a student from the first cohort stated "I think it does in that everybody is an individual, every person is different um and while maybe you don't um change what you do, I think you can change the way that you maybe deal with people, treat people um according to yeah how they are".(F13:2) Another student from the second cohort identified the importance of understanding the details of each individual patient in order to provide appropriate care: "I need to ..know the patients, their circumstances, how they're living, the previous life and that's how I think I could provide them with the care they want (F14:22). 


\section{Learning nursing.}

Both cohorts of students overwhelmingly appreciated their study programme reinforcing the values expected as a professional nurse, both in theory and applying them in practice: "I think that the programme has literally taught me everything like ...strengthened the core sort of values inside and I didn't realise that until the $3^{\text {rd }}$ year when it's all come together" (F13:2).

Both cohorts recognised the power of knowledge, with some appreciating the importance of higher education to develop their skills of critical thinking and research. They welcomed the emphasis on the values base necessary for professional practice, with those studying for a degree, the importance of an evidence base: "I think it's really important to do it [degree studies] because it kind of helps us develop the qualities, especially the compassion, the caring, the how to take care of patients in proper way (F14:22).

They also recognised the importance of lifelong learning in aspiring to be the best, and the impact of learning on their personal development: "I do feel like I'm a product of my.... education in the sense that I've taken everything that you guys have given me. I've tried to learn from .. and.. sort of, harness all of that information... and use it. ...l wanted to be able to be the best that I could....so ..I listened and.. so it's almost like ..you're the key, I've got the lock (F14:14).

A common response from both cohorts was the notion of learning not to be judgemental and recognising just how the programme has developed their understanding of patients as people: "I developed as a person. I feel like more mature in understanding things and I feel it helped me with...I'm not saying that I've been... judgmental before, but it helped me in understanding everyone in... a good way.... seeing people as human beings, not as conditions .. not as numbers...it did help me a lot with that. When I started ... as healthcare assistant it was completely different. It was ...go in there doing the task, you know, not thinking about the poor patient (F14:22). 
Whilst role models helped students understand the realities of practice, they learned from both good and bad practice "I've seen some amazing role models, and.. I've seen the nurses that I never ever want to become." (F14:19, p2). In the Feb 14 group, the programme modules which considered humanisation in particular were particularly valued "It's something that made a big difference. I think it changed me as a person, how I see things now; I wasn't like this before (F14:22). The programme "opened my eyes to a lot of things" (F14:22) and in particular helped them develop the qualities that make a 'good' nurse through reading and practice experience. Most importantly, the programme helped each student develop themselves as individuals: "I think the programme has definitely changed me, it's changed how I see life, it's changed how I see other people, how I relate to people um and that's probably the aspect of the course that I hadn't necessarily anticipated" (F13:2).

\section{Personal journey}

Since the beginning of their journey, a common view of students from both cohorts was the desire to make a difference to people's lives and this was as true at the end of their programme. However, now, as they were about to qualify, they realised the increased level of responsibility expected of them, and although they remain excited, they were beginning to feel daunted at the prospect of Registration. From entering their programme, some from both cohorts expressed their greater understanding of what a qualified nurse actually does, the complexity of the role and the workload and responsibilities "I don't think I quite realised the extent of how you can help people and in what different ways...." (F13:1). The F14 cohort, a younger student group on the whole, more fully expressed their increasing confidence to succeed and several of them sought to extend themselves and their ambitions to move forward in their career "So my ambitions have changed since I started the course and I can think of a future beyond staff nurse because I know I can do it now. (F14:8) Another student (F14 cohort) commented on her experience of the last three years reinforcing her achievements and her determination: "I love it, I love everything about nursing... I'm determined. And I will always aspire to be the good nurse... I'd do it ten times over. It's been amazing" (F14:19) 
Others expressed their desire to continue learning once qualified, to be competent and aspire to become a change agent: "I always think is there any way.... can change.. just to make the care better for the patients" (F14:24). So for both groups of students, from a position at phase one of wanting to feel competent and knowledgeable throughout the programme, by phase five students from both cohorts articulated well, their own personal journey, were ambitious to succeed and extend themselves beyond initial registration, to continue learning and act as role models to others.

\section{DISCUSSION}

The findings of the final phase of this five phase study were insightful. Following two cohorts of student nurses each undertaking two distinct curricula, the two main areas arising from the findings were i) the impact of the curricula on students' perception or their values about caring. This area incorporated the themes of 'Articulating the meaning of the terms 'caring' and 'dignity' as well as 'Recognising the need for individualised care' and ii) The impact of the curricula on the students' journey and aspirations of their professional career. This area incorporated the themes of 'Learning Nursing' and the students' own 'Personal Journey'. As previously stated, while both cohorts followed different curricula, the academics teaching them were the same across both programmes and over time, they became immersed in the philosophy of the new humanisation framework which impacted on both cohorts.

\section{The impact of the curricula on students' perception of their values about caring}

Students in this study from both cohorts acknowledged the impact of their curriculum on the development of their personal values, how they were able to better articulate the abstract terms of 'caring' and 'dignity' and how they have changed as individuals in the way they think and act. From an American (USA) perspective, Brown (2011) reinforces the dependency of professional nursing behaviours on teaching and learning interactions that happen in the academic setting and which, she suggests are refined in clinical practice. She further reinforces the importance of caring as a moral imperative in nursing which is developed in the academic environment and emphasises its significance as a core value espoused by the UK (DH 2012) and the USA (Goldenberg \& Dietrich 2002). However, Warne 
et al. (2011) in the UK acknowledge the paradoxical tensions that nurse educators face when designing and implementing the nursing curriculum, with Brown (2011) reinforcing the particular tension between the development of technical competence which potentially dehumanises the nurse's engagement with the patient, and the value of caring. The humanising curriculum in this study presented a real transparency for students and an overt link between the teaching of humanising values and the outcomes of the programme. Students were able to articulate the values underpinning 'good' nursing in their academic assignments, illustrating the achievement of their competence in practice. Therefore the expectations of students learning of theory and practice within the values-based curriculum were not only transparent but they were held accountable for their achievements.

A key feature of this study is the ability of students to articulate what is meant by the terms 'caring' and 'dignity' and exactly what they consider to be the core values of a registered nurse. Murphy et al. (2009) in their quantitative study in England found that the caring behaviours of students in their third year were statistically poorer than those of students in their first year. They recognised the challenges of defining the word 'caring' but cited Woodward (1997) who suggests that it might comprise two components: instrumental (doing physical care) and expressive (dealing with patients' psycho-social and emotional care). However, from this present study, students had developed a different perspective, a philosophical way of being with their patients, linked to their own lifeworld of participating in the study programme. They believed it was a way of building their relationships, empowering them to make their own decisions. They suggest that it is a philosophical approach of seeing the patient as a whole, as a person rather than a patient, respecting the way that they have chosen to live and how they want to be treated. Although Murphy et al's. (2009) study deduced that the educational process seemingly reduced the students' caring behaviours, this present study contradicted this. This study allowed participating students to articulate the concepts in a way they understood, appearing to see the importance of education and its link to caring practice reinforcing the recent NHS initiatives to further support the notion of individualised and humanised care (DH 2012). 


\section{The impact of the curricula on the students' journey and aspirations of their professional}

\section{career}

This area incorporated the themes of 'Learning Nursing' and their 'Personal Journey'. Leaving the programme with a more confident attitude to patients, students in this study, although daunted by their proximity to becoming a registered nurse, began to think of their future. Both curricula from each of the F13 and F14 students sparked in them a real desire to become a 'good' nurse and for some, to continue learning so that they can influence and enhance care through being role models themselves. This sense of a new generation nurse and their aspirations and hopes of a bright future and a belief that they can influence, contradict the observations by Watson (2009) in the USA. Watson suggests that for those nurses who are not able to practise caring due to the high through-put of patients, heavy patient load, staff shortages and unrealistic targets "can become hardened, brittle, worn down, and robot-like" (p467), rather like those nurses illustrated in the Francis Report (2013) in England some four years later. As identified in the introduction, the outcome of the Francis Report (2013) stimulated a national flurry of activity towards a values-based recruitment of all staff employed in the NHS including those candidates applying for a place on a nursing degree. Additionally the proliferation of reviews and reports extended globally towards a myriad of recommendations and policy documents. Some five years since Francis (2013) published his report and the commencement of the humanised curriculum in this study, it is reassuring that these students have aspirations and a determination to "make the care better for the patients" (F14:22).

Several students in this study stated that the educational programme significantly changed them as individuals, how they think about others and how they relate to them and that this was unexpected. These students appear to have embraced a caring pedagogy alongside the value of graduate study as Brown (2011) advocates; a pedagogy that purposely integrates affective objectives with expected outcomes for graduate nurses, which she suggests challenges many nursing curriculum designers. Ingrams (2016) in her international review of graduate-level entry to nursing, found that in the USA and Australia, the graduate nurse was valued, not only for their level of critical thinking and decision-making but for their ability to act as patient advocate. In particular, they valued graduate nurses as 'thinking nurses', and 
after the first year of qualifying, excelled way ahead of non-graduates, being pro-active, deep learners who are socialised in their ability to act as future leaders in the profession. As Francis (2013) reports that the culture of an organisation is informed by the nature of its leadership where the leadership of the Mid Staffordshire hospital was 'significantly lacking'. This study reinforces these students' aspirations to succeed, their determination to find ways to influence care, recognising their own impact on others and the values they have grown through the curriculum.

\section{Limitations of the study}

There are a number of limitations to this study which require the reader to be cautious when interpreting the findings. It is well recognised that there is a tendency for the fall-out rate of participants from longitudinal studies to be high and, as in this study, may fail to necessarily reflect the views of the majority in the cohort (Bowling 1997). However, this is balanced against the five data sets collected from each individual along with data saturation when analysing the findings which adds strength to the study. Future studies may seek to extend the work following up the same students one year following qualification to determine any changes in their views following socialisation into the culture of their workplace.

\section{CONCLUSION}

This study tells a positive story. In spite of the rhetoric about values-based curricula, there has been little evidence to date, of its impact. Although longitudinal qualitative studies are rare, this study adds to the body of knowledge on the perceptions of two groups of students on the development of their caring values during their undergraduate programme. In spite of experiencing two different curricula, one based on a philosophy of person-centred care and the other based on the humanising values framework (Todres et al. 2009), both groups were influenced by their exposure to the same educators who had embraced the new humanisation philosophy. In their final one-to-one interview, they each reinforced the value they gained from their education, recognising just how they had changed as individuals and determined to influence the quality of care. However, once socialised into the practice setting and feeling the impact of the staff shortages well recognised by Finlayson et al 
(2002), it would be interesting to follow the students through to the end of the first year following qualification to identify any changes in their perceptions. Extending the study to more settings in other HEls in different parts of the country would perhaps identify any similarities or differences elsewhere, particularly given the national impact of the NHS Constitution (DH 2015).

\section{References}

Aupia, A., Lee, T., Liu, C., Wu, S.V., Mills, M.E. 2017. Caring behavior perceived by nurses patients and nursing students in Indonesia. Journal of Professional Nursing, 34(4) 314-319 Accessed at https://www.sciencedirect.com/science/article/pii/S8755722316302125

Berwick, R. 2013. A promise to learn - a commitment to act: Improving the safety of patients in England. National Advisory Group on the Safety of Patients in England. August. Crown Copyright, London. Accessed at https://www.gov.uk/government/uploads/system/uploads/attachment data/file/ 226703/Berwick Report.pdf

Bowling, A. 1997. Research Methods in Health: Investigating Health and Health Services. Open University Press, Buckingham.

Braun, V., Clarke, V., 2006. Using thematic analysis in psychology. Qualitative Research in Psychology 3, 77-101.

Brown, L.P. 2011. Revisiting our roots: Caring in nursing curriculum design. Nurse Education in Practice, 11, 360-364.

Cohen, L., Manion, L., Morrison, K., 2007. Research Methods in Education. Routledge, London.

Day, R.A., Field, P.A., Campbell, I.E. \& Reutter, L. 2005. Students' evolving beliefs about nursing: from entry to graduation in a four-year baccalaureate programme. Nurse Education Today, 25(8), 636-643.

Department of Health 2012. Compassion in Practice; Nursing, Midwifery and Care Staff: Our vision and strategy. Accessed at: http://www.nhsemployers.org/yourworkforce/plan/nursing-workforce/compassion-in-practice 
Department of Health 2015. The NHS Constitution for England. Accessed at https://www.gov.uk/government/publications/the-nhs-constitution-for-england

Finlayson, B., Dixon, J., Meadows, S. and Blair, G. 2002. Mind the gap: the policy response to the NHS nursing shortage. British Medical Journal, 325(7363), 541-544

Francis, R., 2013. Report of the Mid Staffordshire NHS Foundation Trust Public Inquiry: Executive summary. The Stationery Office, London.

Goldenberg, D. and Dietrich, P. 2002. A humanistic-educative approach to evaluation in nurse education. Nurse Education Today, 22(4), 301-310.

Health Education England 2015. Raising the Bar. Shape of Caring: A Review of the Future Education and Training of Registered Nurses and Care assistants. Accessed at: https://hee.nhs.uk/our-work/developing-our-workforce/nursing/shape-caringreview

Health Education England 2016. Values Based Recruitment. Accessed at: https://www.hee.nhs.uk/our-work/values-based-recruitment

Holloway, I and Wheeler, S., 2010. Qualitative Research in Nursing and Healthcare. WileyBlackwell.

Ingrams, P. 2016. Graduate-level entry to nursing: international perspectives. British Journal of Nursing, 25(10), $560-561$.

Keogh B. 2013. Review into the Quality of Care and Treatment provided by 14 Hospital Trusts in England. Accessed at http://www.nhs.uk/NHSEngland/bruce-keoghreview/Documents/outcomes/keogh-review-final-report.pdf

Mackintosh, C. 2006. Caring: The socialisation of pre-registration student nurses: A longitudinal qualitative descriptive study. International Journal of Nursing Studies, 43, 953-962

Murphy, F., Jones, S., Edwards, M., James, J. and Mayer, A. 2009. The impact of nurse education on the caring behaviours of nursing students. Nurse Education Today, 29, 254-264.

Neale, B., 2013. Adding Time into the Mix: Stakeholder Ethics in Qualitative Longitudinal Research. Methodological Innovations Online 8 (2), 6-20.

Nursing and Midwifery Council (NMC) 2010. Standards for pre-registration nursing education.

Accessed

at: 
https://www.nmc.org.uk/globalassets/sitedocuments/standards/nmc-standards-forpre-registration-nursing-education.pdf

Phillips, J., Cooper, K., Rosser, E., Scammell, J., Heaslip, V., White, S., Donaldson, I., Jack, E., Hemingway, A Harding, A. 2015. An exploration of the perceptions of caring held by students entering nursing programmes in the United Kingdom: A longitudinal qualitative study phase 1. Nurse Education in Practice, published online, May 16, 15(6) $403 \quad$ - 408 Accessed 4 from: http://www.nurseeducationinpractice.com/article/S1471-5953(15)00085-2/abstract

Royal College of Nursing 2012. Quality with Compassion: the future of nurse education. Report of the Willis Commission on Nursing Education. Royal College of Nursing, London. Accessed at: https://www.scribd.com/document/154481713/WillisCommission-2012

Salehian, M., Heydari, A., Aghebati, N., Moonaghi, H.K. 2017. Faculty-Student Caring Interaction in Nursing Education: An integrative Review. Journal of Caring Sciences, 6(3), 257-267

Scammell, J and Tait, D., 2014. Using humanising values to support care. Nursing Times, 110 (15), 16-18.

The King's Fund 2013. Patient-centred leadership: Rediscovering our purpose. The King's Fund, London.

Todres, L., Galvin,, K.T. and Holloway, I. 2009. The humanization of healthcare: A value framework for qualitative research. International Journal of Qualitative Studies on Health and Well-being. 4, 68-77

Warne, T., Holland, K., McAndrew, S., 2011. The catcher in the why: Developing an evidence-based approach to the organization, delivery and evaluation of preregistration nurse educational programmes. Nurse Education in Practice (11), 131135.

Watson, J. 2009. Caring Science and Human Caring Theory: Transforming Personal and Professional Practices of Nursing and Healthcare. Journal of Health and Human Services Administration, Spring, p466-482. 
Woodward, V.M. 1997. Professional Caring: a contradiction in terms? Journal of Advanced Nursing, 26(5), 999-1004. Accessed at https://onlinelibrary.wiley.com/doi/full/10.1046/j.1365-2648.1997.00389.x 